\title{
Built Environment Psychology A Complex Affair of Buildings and User
}

\author{
Safiullah $^{\# 1}$, Prof. (Dr.) Ashutosh Sharma ${ }^{* 2}$ \\ \# Department of Architecture and Planning, \\ Maulana Azad National Institute of Technology, Bhopal, India \\ ${ }^{1}$ safi@iul.ac.in \\ * Department of Architecture and Planning \\ Maulana Azad National Institute of Technology, Bhopal, India \\ 22ashutosh9826055792@gmail.com
}

\begin{abstract}
Every built form has the latent to create an environment which mould/ form the user behavior accordingly, in other hand, user behavior shapes the environment to perform their activity; and ultimately achieve their level of desire. As the term used is 'Built form'; it is obvious that some kind of architecture happen. Again, the term architecture means combination of generic elements with respect to "Human Behavior", “Technology", and "Aesthetics". It implies that, built form is directly proportionate to the human behavior, applicable technology, and aesthetics. With this paper attempt has been made to look into theories \& concepts; in result and analyze the relationship between built environment and human behavior, technology \& aesthetics, their settings. Further, components of human behavior have been explored primarily, as how they plays their role or how they establish their communication system with the user for desired built environment.
\end{abstract}

Keyword - Built Environment, Behavioral psychology, Physical setting, Environmental Communication, Public space

\section{INTRODUCTION}

Human behavior, experiences, social and cultural occurrence are believed to be the outcome of the built environment of any particular area. It means, to maintain the balance and regain the actual definition of healthy built environment, it is necessary to identify the factors involved. Built environment is defined in 'Collins English Dictionary' as 'the buildings and all other things constructed by human beings', which implies as the environment made by the architecture of multiple buildings and built-up things, come up to satisfy the human needs and demands initiated by human physiology, sociology, psychology or all.

The purpose of architecture is to give order to various components evolved through the human needs and demands. In architecture, the basic generic elements such as line, plane, surface, mass, volume, material and structure; when constitute, combine and interact; it gets some form, which has some exceptional physical and visual character. The physical appearance and visual impact not only help engage the user with its content, but also allows the user to use his/her senses to recognize the function of a place (Matravers 1998).

Since every element has some psychological impact, establishing a kind of communication with the user; Architecture occupies and shapes the physical social context as well as influencing perception which in turn influences human behavior (Rapoport 1990).

The studies in the field of environmental psychology has mostly focused on residential units, interiors of the dwellings, parks or sometimes studies have been done on behavioral studies, or only in context of psychology or architecture alone; but when it comes to heart of any neighbourhood, i.e. urban public space, the number of these studies decreases dramatically and it can be considered as a gap in literature of the built environment. Additionally, most studies in the field of architecture, planning or psychology or interdisciplinary study have overlooked the importance of physical setting of built form; and specially in case of urban public spaces.

The aim of this study is to find the scope of built environment, its way of interaction to the user, and spot the components in establishing the complex relationship of interface. Further the primary piers have been identified of the interface. Identified component as 'place' has been reviewed in its second fold, and its suitability has been examined through various parameters starting from its history to present scenario.

\section{BUILT ENVIRONMENT AND ITS UMBRELLA}

The Term 'built environment' refers to the surroundings made for the Human, by the human and to be used for human. This could be well understood through an example. If we take the example of the surrounding made during this reading time, we can see the books, notes, computer systems, gadgets, internet etc.; we are surrounded by so many things which are the ultimate product of dozen or hundred of material products and product systems. These actually are the part of our surrounded micro environment. Likewise, if you open your window and see outside, what you find, that is none other than the green landscaped patch, few trees, plants, 
some vehicles, human beings in clusters and perform some activities, some metallic roads, some bridges, variety of buildings, some vendors with their own territorial space, few animals, and so on, and this continues. As seen in the example, this could be observed that we build the things and therefore make important contributions to the built environment; we design and build our lives from one experience to another. Based on these experiences; components of the built environment emerge from human needs, thoughts and actions. Sometimes the substances of human actions are grand, and we design and plan quality life experiences for ourselves and others; in other hand, these actions could be short-sighted, creating uncomfortable situation that are less fit for healthy human activities and negatively impact the surrounding environments. It means each aspect of built environment is created to fulfill human purpose and their need. This could be well concluded as:

- The Built environment is everything humanly made, arranged, or maintained;

- To fulfil human purposes (needs, wants, and values);

- To mediate the overall environment; and

- With result that affect the environmental context

In terms of man-made weather shields (built form), we can easily represent the equation as the built environment is the set of so many subsets e.g. Interiors, structures, landscapes, cities, regions, earth etc. The complexity of the components will depend on their needs and demands, which varies physiologically, socially and psychologically (Figure 1). The complexity will also depend on its magnitude which may vary from place to place, point to point or area to area, time to time. With this figure we can easily understand the type of the human need and their levels and how they are manifested in the built environment.

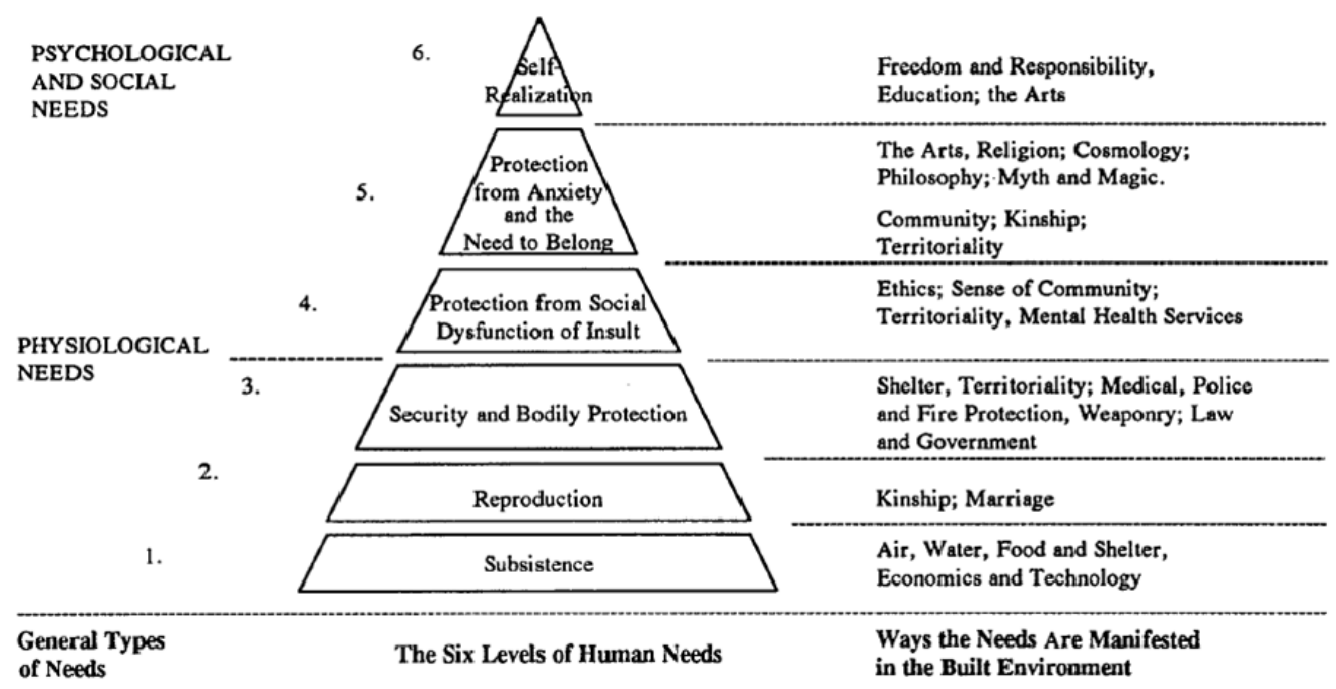

Fig. 1. Human Needs and ways they are manifested in the built environment (Source: Bartuska Tom J, 2007)

\section{A. Components and their communication}

Every built form has a unique nature which could be easily perceived by the user and accordingly they prefer to go and enjoy. Now, why this question of selection arises, when this is the ultimate result of their need itself. Actually this is true that, they prefer or not prefer to go amongst their own creations but, this happens because the said built patch is satisfying their single parameter of physiological need, while the other parameter of psychology is somehow overlooked.

Every element such as line, plane, surface, mass, volume, material and structure; has the contribution of their unique identity in formation of physical or visual character in the architecture of any area, means beside the individual building, the arrangement of buildings (architecture) also matters which is being overlooked somehow and affects the usability of area and not being choose by the user; in result, most of our urban spaces / built forms of the Indian cities or either underperforming or over crowded.

The term 'psychological need' which have the number of synonyms as 'user need in context to their psychology'; or the 'environmental-behavior studies'; or in terms of research it is called 'environmental psychology'; which is the matter of concern now. Environmental psychology is the field of study that examines the interrelationship between environments and human affect, cognition, and behavior (Bechtel\& Churchman 2002; Gifford 2007; Stokols \&Altman 1987). It means interrelationship (architecture) of the various components and elements of the built environment is to be taken care of for making the environmental psychology more appealing. 
Since the time of Vitruvius thoughts; first century B.C., when he had given the basics for architecture to suits the human behavior and make more appealing architecture of the environment; so many influencing factors have generated. Amongst that, three basic factors have been recognized which influence the architecture of any region viz a viz Utilitas, Firmitas, and Venustas, or in our language, it is 'Human Behavior (function)', 'Technology', and 'Aesthetics'. (Moore G.T., 1979). As the word has become more complex and the complete griping over all three domains is very difficult, it is obvious to get succeeded with more command over the more number of domains. It means for better psychological environment, we would have to work on their basic influencing factors which directly interact to the users; but how? If we design a site or arranging a solid void ground picture or interiors of any space; we actually see the way of communication and how good or rude that communication of the various spaces with the users is? In our designing that mode of communication varies in respect to the type of user i.e. who actually the user are? Whether he or she is old, young or child, whether he or she is physically fit or challenged, and so on. Likewise we can identify the real relationship of the various variables; and their associated functions viz-a-viz circulation flow, proximities between activities, symbolic values of the enclosure, form, its embodied technology, and aesthetics etc., all these turn into the commuters' behavior, and physical environment.

\section{B. Evaluation Method of environmental psychology}

The impacts of the physical environment; or the desire human behavior components, could be done through either ways i.e. result could be obtained by studying the existing built blocks, their environments. User reactions or satisfaction level could be seen in respect to the various identified variables as discussed earlier, and further same or the required moderation could be done to achieve the desired level of psychological environment which will be the true indication of user behavior. The other way is just opposite to this, where we can study and analyze the behavioral information of the user, and take up the actions for making/ moderating our built form accordingly to achieve the desired level of satisfaction.

Actually the evaluation of the environmental behavior components and its outcome is a task which can better assessed through post occupancy surveys and data. The environmental psychology is not the field which can be assessed and concluded through a simple task rather an environmental psychologist should go on site of question and feel the environment personally, It is not the subject which can be expressed through some very creative or very sensational writing rather to sketch the environment and clicking of photographs of various time spans, various occasions, of various moods i.e. with the series of photographs. In order to look at environmental behavior studies in architecture, we must understand two conceptual frameworks, one illustrating the range of environment-behavior information available, and the other showing where in the design process environmentalbehavior information most affects architectural decision making (.Moore G.T., 1979)

\section{Behavioral information and settings}

A useful model for seeing the scope of available environmental-behavior information, first proposed by the architectural psychologist Irwin Altman (Figure 2), includes three main components: 'environmental-behavior phenomena', 'user group', and 'settings'.

- 'Phenomena' include the different aspect of human behavior in relation to the everyday physical environment e.g. Proxemics, Privacy, Environmental meaning and symbolism.

- Different 'user group' has the different way of do's and don'ts; way of perceiving; interpretation and finally responds. Carefully classified user group with respect to the ethnic and special; and their behavioral information could be the wealth for a researcher.

- 'Place' is another aspect of setting in making of appropriate permutation/ combination for the user-group to its development typology i.e. what behavioral phenomena could be taken care for respective user group to achieve the desired environment at any particular place.

The ultimate objective of the collection of behavioral information through different-different ways is to produce an ultimate design form of the environment, which could satisfy the human behavior. The rightness of the design form depends on the degree to which it fits its behavioral, social and cultural aspect, along with the setting of the components. In other hand if some misfits exists in this setting, the form become inappropriate and do not perform as desired. These two fundamental concepts are the basics of any arrangement / architecture, and evolve the design form through the form-behavioral relationships. Further this human-behavior information has been established on the following identified piers.

1) Anthropometric: Some time we call it as 'Human factors', 'ergonomics'; which deals with the dimensions of the human body and its other physiological characteristics and abilities of user (human being) in various conditions and micro environments. 
2) Variety of space: It has the variety of massages which are hidden; this hidden dimension of the spaces which speaks to the user and makes the situation favourable or un-favourable to them for the particular usage. This communication of the spaces depends upon the range of shapes, sizes, and positions. Example: No couple would prefer to sit over the eight seated sofa, if they find a two seated cosy seating space in some dim light corner. Would you prefer to stand and talk with someone at just the middle of pedestrian road, obviously not; and you would shift to the edge or near to some kiosk area (may be near to any tree or plant or less crowded patch)....why? That is because of the hidden communication of repletion by that mid rode space for your purpose. In the early 1950, Robert Sommer, an environmental psychologist; studies the spatial factor in different types of face-to-face interactions at various venues, shapes of spaces, size of spaces; and found the proxemics.

3) Personal Space: I would share my experience here as some time I fought with my elder brother during my child age for his encroachment over my area of bed; though it was all ours. Actually this fight was to save my personal space. Robert Sommer defines this personal space as a small, invisible protective sphere or bubble that an organism carries about and maintain between the self and other, that is a body buffer zone of personal not shared space; this personal space is dynamic and varies according to individual's personality, mood, age, sex and their social and cultural rules.

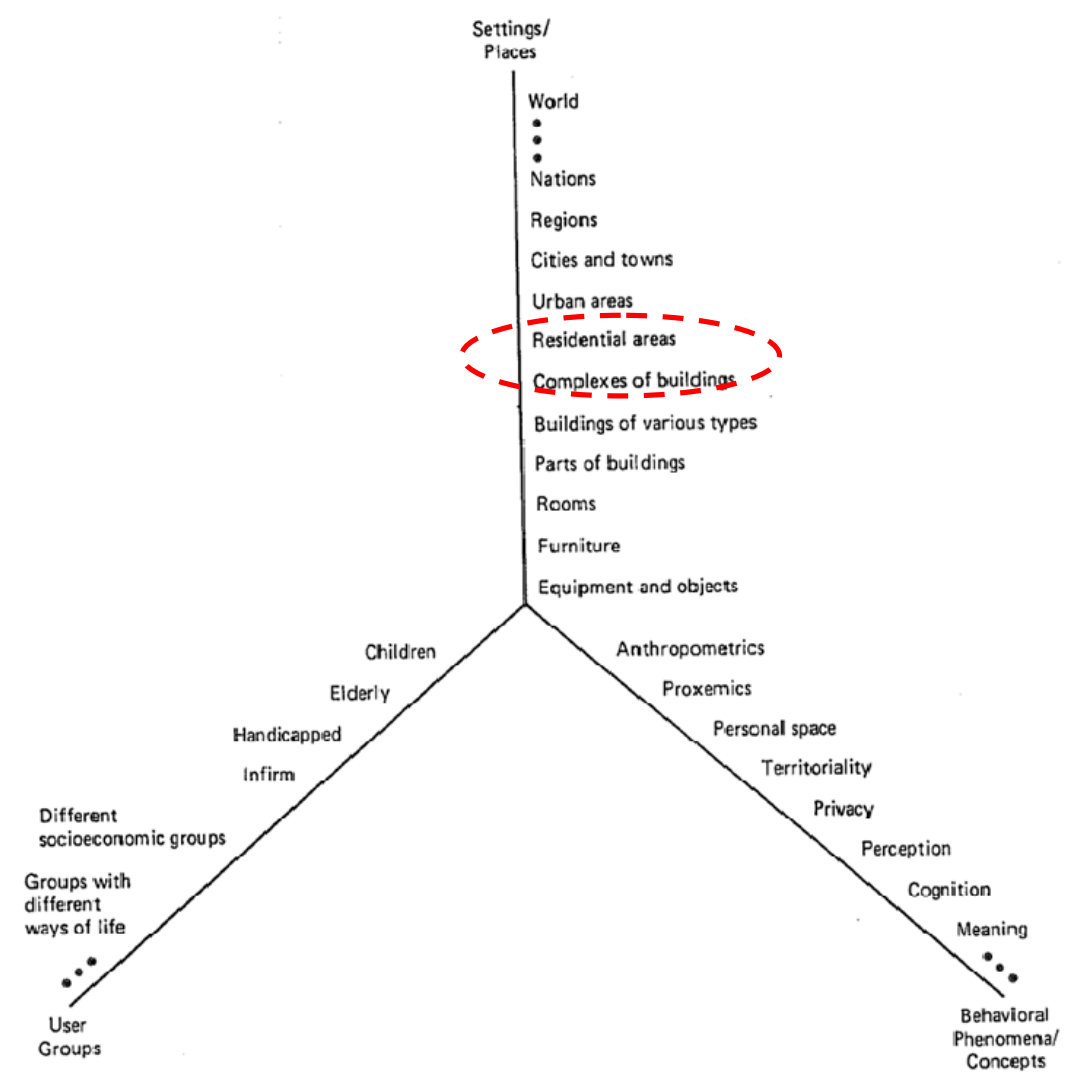

Fig. 2. Human Human-Behaviour information and its scope (Source: Altman Irwin, 1977)

4) Territory: This refers to a group of behavior setting that a person will personalize, may own, and defend (Environmental-behavior studies by G.T. Moore). During your shopping you frequently saw the situation of fighting for two shopkeepers for having their signage stands at their fronts, though that front area is of public; actually they fight to defend their territory and made each other feel about sense of ownership.

5) Defensible space; The term created by the architectural designer and researcher Oscar Newman, though the concept had already been set down by Jane Jacob in her book 'The death and life of great American cities'.

6) Privacy, Density, Crowding and Stress: The control of access or in other hand the level of your accessibility is term as Privacy which further categories as Public, semi public or private space according to this level. Density id the mathematical measures of the numbers per unit area while the crowding is in context of psychology or environmental-behavior concept which refers the experience of being hemmed in, blocked or suffocated. Crowding is the result of perceived density while; treating crowding as a result of failure to achieve desired level of privacy which may result into a stress which depends again on individual personality, mood, age, and sex. 
7) Environmental perception: This is always an issue of debate about the difference of perception between architects and users. My opinion is definitely differences exist about the perceptions gained. Some time architects implement some material like concrete, wood, brick or glass in expose condition may be because of truthiness or honesty of the materials e.g. Le-Corbusier' Chandigarh, Jaipur etc.; but the users opinion is something negative like cheap look, cost cutting, vagueness or dullness etc. To date, principles of visual perception called gestalt theory have been the most used by architectural theoretician and researchers as basis for predicting building perception. The principle that have been most applied include figure and ground, pragnanz or completeness, relatively simplicity, proximity, equality, continuity, and closure. Other principals include the cues for depth perception- interposition visual angle and distance, linear perspective, aerial perspective, light and shade, movement parallax, and texture gradients.

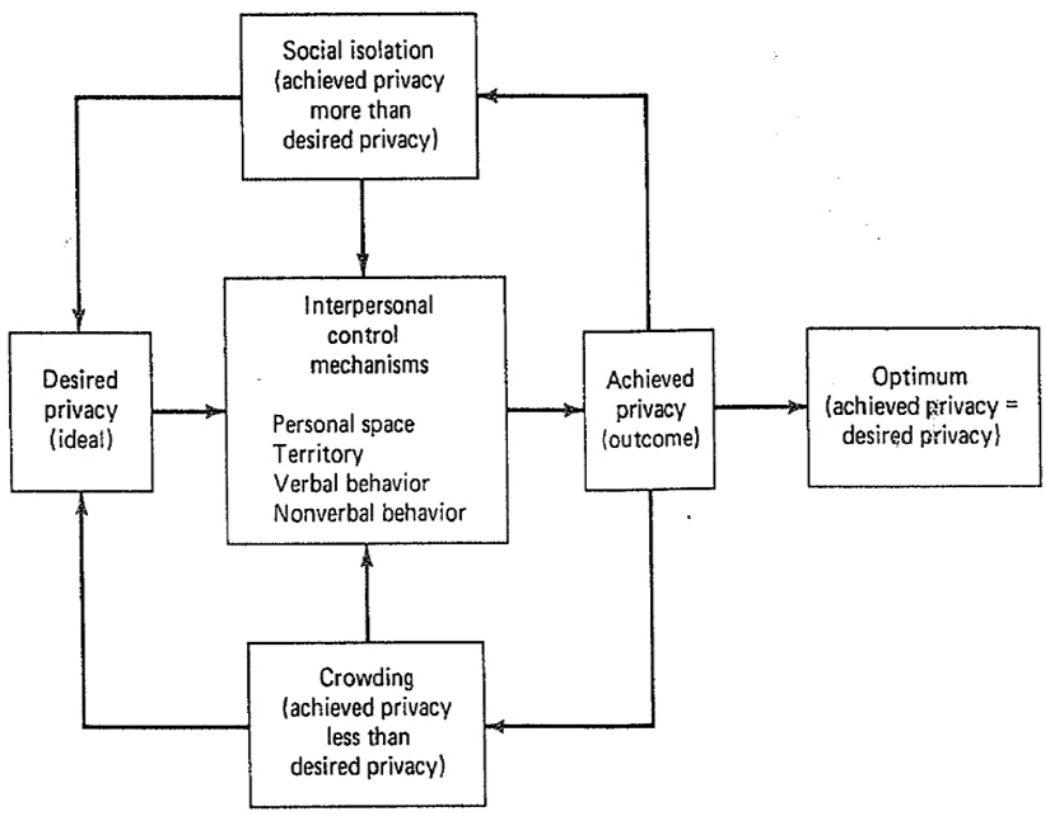

Fig. 3. Privacy, personal space, territory, and crowding (Source: Altman Irwin, 1977)

8) Environmental Cognition: Peoples image of the building, cities or regions basically serves three functions as they simplify the area into a chunks of memory, give meaning to the word by personalizing the buildings, and make them, in effect, one's own; and they give framework for group communication based on shared experience and sentiments. There are four types of images that are part of people's environmental cognition:

- Urban cognitive mapping, subjective knowledge of the spatial layout or the feature of the building. This includes the building imagery; and urban cognitive mapping which is best known illustrated in Kevin Lynch's Image of the City.

- Impression of the character or overall image of various cities or buildings within one city.

- Linguistic category system-basic ways of thinking about the environment and about the people on land.

- Meaning, sentiments and the symbolism.

\section{Place of a public Place}

An easy way to comply with the conference paper formatting requirements is to use this document as a template and simply type your text into it.

If we look into the model for Human-Behavior information, suggested by Irwin Altman; another major pier beside the 'phenomena' and 'user group', is the 'place'. The setting in environmental psychology could change in respect to the place also, because every place and its expectations are different and unique and that is the result of changed human behavior. Before establishing an ideal or more appropriate setting for the human behavior, it is important to take the 'place' as important variable in consideration.

Related studies have focused mostly on building parts and that varies between interior to exterior of the buildings or some time the complexes of buildings, but when we see the study related to urban spaces which is supposed to be the more relevant in context to the human social and cultural aspect, allied issues such as mobility, uneven density, centralization of activities, image of city etc.; and can contributes a lot in smart Indian cities mission,; reduce dramatically. In view of this, urban public spaces could be taken as thrust area in today's context. 
There is a popular notion about the public place/ space as that is like a stage of any auditorium or theatre surrounded by audience; and I too agree with this. Public space is described as theatrical like setting by French (1978), Whyte (11988), Carr et al. (1992), Engwicht (1999) and more recently Cousseran (2006). The idea behind this notion is actually the variety of activity by the variety of users in a variety of ways for expressing their real life freedom, social, and cultural expressions. With this above characteristics it would be quite acceptable as these public space should be free from any hindrance, any encroachments and should be free from any kind of fear like accidents, or discriminations.

Furthermore, in the present context, our modern cities have lost sight of the traditional understanding of public spaces (Rob Krier, 1991). This could be well perceived and understood by the city dwellers who had the experience of their environment, have the strength of character to pronounce sentence on the way things have gone and sensitive enough to compare the condition of those public spaces came out as achievement of their past and present town planning system. Now the question arises as, what are the things or ground comes into the process or concept that brought the public space concept in hotly dispute? We need to think over it.

If we wish to clarify the concept of urban spaces without imposing aesthetic criteria, we are compelled to designate all type of space between building in towns and other localities as urban space (Rob Krier, 1991). Urban spaces are actually the spaces which are geometrically bounded by a variety of elevations (Rob Krier, 1991). The legibility of the space is prominently done through this geometry and aesthetic quality which allows to the people to perceive this external space as urban space.

Polarity of internal-external spaces is constantly in evidence, since both the spaces are governed by some similar principles not only in functions but also in form; Internal spaces are shielded by weather rather than open to sky, have the environment of an effective symbol of privacy rather than unobstructed and open for all; In other hand external spaces have the feeling of large territorial sphere e.g. public, semi public and private zones. In all above we can see somehow the geometrical permutation and combination of spaces.

Now the question of aesthetic characteristics, which can be categorized into precise aesthetic and confused emotional factors; based on its analysis which depends on subjective questions of visual and sensory habits of one individual to next, Socio-political and cultural attitudes (Rob Krier, 1991). Historical evidences of public spaces in context to above said parameters could easily reinforce and reflects the same. If we recall or question to self about the historical background of the towns layout e.g. identity of form, content, and meaning; we must be more exact in asking (Rob Krier, 1991):

- Was the resulting from the free expression of the creative artist?

- Alternatively, were the artistic wishes of the employing class imposed on the artist, and was they forced to adopt their notion of form?

- Do contemporaneous periods exist, which on the basis of different cultural traditions in different countries or continents where similar social conditions prevail, produce the same artistic solutions?

- Alternatively, are there non-contemporaneous periods which led to fundamentally different artistic solutions, each being a stage in the development of the same cultural tradition in the same country under the same conditioning social factors?

With the above question some very noticeable and relevant keywords can be extracted as: aesthetics, artist, patron, social environment, leeway given to artistic expression, formal restriction imposed by the patron, formal restrictions imposed by the social environment, fashion, management, level of development, technology and its potential applications, general cultural conditions, scientific knowledge, enlightenment, nature, landscape, climate etc; which can't be considered in isolation and are completely inter dependent.

\section{Discussion}

Every built form would have some kind of environment which may be good or bad and that will depend on the communication system between the built form and user. When the term built form comes, it means some architecture exists, which arrange the built blocks and other participating components in some order; and allow the users to use senses to recognize the function of a place. The question arises now, what factor should be consider and how? With this manuscript, attempt has been made to identify the area to be focus and further their basic components i.e. fundamentals. With the related theories; 'Human behavior', 'Technology', and 'Aesthetics' have been identified as the major pier for the architecture of built form. The term human behavior again is the set of some subsets, which have been identified as 'User Group', 'Behavioral Information', and 'Place'. Further, Place has been identified as 'Urban Spaces' which would be more appropriate in milieu. In context to identified place; user type has been selected as 'general user type', and their behavioral information have been extracted as 'phenomena'. This study actually lays a foundation for the future research and contributes in the mission of making the cities 'smart' word wide. 


\section{ACKNOWLEDGMENT}

We thank the anonymous referees for their useful suggestions, critic and content; along with my department at Maulana Azad National Institute of Technology, Bhopal, India. This would be incomplete without the name of Department of Architecture and planning, Integral University, Lucknow, India.

\section{REFERENCES}

[1] Bartuska, Tom J., McClure W. R., 2007, the built environment: A Collaborative Inquiry into Design and Planning, USA: John Wiley

[2] Gifford, R., 1987, Environmental psychology, Principles and practice, Massachusetts, Allyn \& Pacon. Inc.

[3] Altman Irwin, 1977, Privacy regulation: Culturally universal or culturally specific? journal of social issues, 33:66-84

[4] Moore. G., Architecture and Human Behavior: The place of environment-behavior studies in architecture, issue September 1979, Wisconsinarchitect,accessed09March2016,

<https://www.google.co.in/url?sa=t\&source=web\&rct=j\&url=http://sydney.edu.au/architecture/documents/staff/garymoore/28.pdf\&ve d=0ahUKEwjF9fKMwpDOahUKOY8KHTWyBkOQFggnMA>

[5] Vitruvius. 1991 Ten Books On Architecture. Edited by Ingrid D. Roland and Thomas Noble Howe. Cambridge: Cambridge University Press.

[6] Leila Mahmoudi Farhani, Mirjana Lozanovska, A frame work for explaining the sense of community and social life in residential environment, issue-3, November 2014, Archnet-IJAR, 223-237

[7] Rapoport, Amos . 1990. The Meaning Of The Built Environment: A Non Verbal Communication Approach. Tucson : University of Arizona Press.

[8] Lynch, Kevin, 1972, What time is this place?, MIT Press

[9] Moore. G., 1979, Introduction to architecture, environmental-behavior studies (chapter 3), edited by Snyder j.c.,Catanese A.J., Mc Graw-Hill book Company

[10] Gifford, R., 1983. The experience of personal space: Perception of interpersonal distance. Journal of Nonverbal Behavior, 7(3), 170178

[11] Krier Rob, 1991, Urban Spaces, Hong Kong, Academy Edition

[12] Moore, G. T., Tuttle, D., \& Howel, S.,1985, Environmental design research directions. New York: Praeger.

[13] Moore, G. T.,1986, Effects of the spatial definition of behavior settings on children's behavior: A quasi experimental field study. Journal of Environmental Psychology, 6, 205-233.

[14] Moore, G.T.,1987. Environment and behavior research in North America. In Stocols, D. \& Altman, I. (Eds.), Handbook of environmental psychology. New York: John Willey.

[15] Lynch, Kevin, 1960, the image of the city, Cambridge MA, MIT Press

[16] Maria Amrigo, Aragones Juan I., A theoretical and methodological approach to study of residential satisfaction, March 1997, Journal of environmental psychology, accessed on 25 may 2016.

\section{AUTHOR PROFILE}

Safiullah, Research Scholar, Department of Architecture and Planning, Maulana Azad National Institute of Technology, Bhopal, India, Email address: safi@iul.ac.in

Ashutosh Sharma, Professor, Dr., Department of Architecture and Planning, Maulana Azad National Institute of Technology, Bhopal, India, Email address: ashutosh9826055792@gmail.com 